\section{Commentary: Recognition is the first step}

\author{
Stephanie H. Chang, MD, and Deane E. Smith, MD
}

Awareness of physician burnout has steadily increased, although it remains an underaddressed issue. First described in 1974, burnout is the result of "severe or prolonged stress and anxiety experienced by people working in the healing professions." Not surprisingly, burnout is present at a higher rate amongst surgeons compared with other physicians. ${ }^{2}$ In a recent survey conducted by the Society of Thoracic Surgeons (STS), a majority (55.7\%) of practicing cardiothoracic surgeons felt symptoms of depression or burnout during 2019. ${ }^{3}$ This prevalence highlights the need for addressing burnout in our field.

In a Young Surgeon's Note, Swain and colleagues ${ }^{4}$ discuss cardiothoracic surgery trainee burnout, as well as potential management strategies. Through different vignettes, they explore circumstances that arise throughout training, such as dealing with bad patient outcomes, experiencing uncertainty in a given career path, losing work-life balance, and feeling like "an outsider" or lacking comradery. The influence of this article extends beyond offering coping mechanisms. It identifies scenarios and emotions encountered by trainees that are infrequently recognized as common experiences and early signs of burnout. Hopefully, readers will gain insight and recognize if they are among the majority of cardiothoracic surgeons experiencing burnout. Additionally, trainees and surgeons alike should realize that the spectrum of emotions elicited by burnout is not unique to them and their situation, but rather common among surgeons.

The follow-up to this Young Surgeon's Note should include what the training community will do to heed the warning. How will we provide trainees with the tools to help them cope with these emotions? First, we should train the trainers so that program directors and teaching

\footnotetext{
From the Division of Thoracic Surgery, Department of Cardiothoracic Surgery, New York University Langone Health, New York, NY.

Disclosures: The authors reported no conflicts of interest.

The Journal policy requires editors and reviewers to disclose conflicts of interest and to decline handling or reviewing manuscripts for which they may have a conflict of interest. The editors and reviewers of this article have no conflicts of interest.

Received for publication July 6, 2020; revisions received July 6, 2020; accepted for publication July 6, 2020; available ahead of print July 13, 2020.

Address for reprints: Stephanie H. Chang, MD, Division of Thoracic Surgery, Department of Cardiothoracic Surgery, New York University Langone Health, 530 First Ave, Suite 9V, New York, NY 10016 (E-mail: stephanie.chang@nyulangone.org). J Thorac Cardiovasc Surg 2021;162:643-4 $0022-5223 / \$ 36.00$

Copyright (C) 2020 by The American Association for Thoracic Surgery https://doi.org/10.1016/j.jtcvs.2020.07.024
}

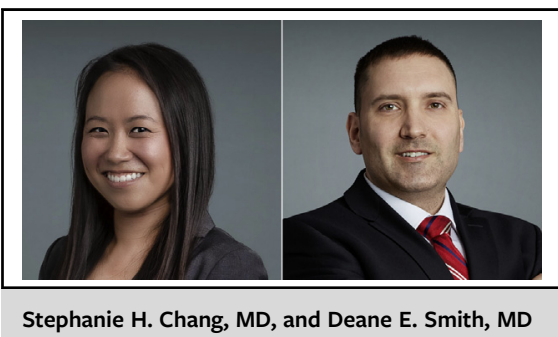

CENTRAL MESSAGE

Recognition of burnout during cardiothoracic surgery training is imperative to help future surgeons develop the relationships and coping mechanisms needed for a successful career.

faculty can recognize the different manifestations of burnout; namely, exhaustion, cynicism, and inefficiency. ${ }^{5}$ With this knowledge, programs can identify trainees struggling with burnout and provide them with the support they need. Additionally, equipping trainees with the skills to identify the symptoms of burnout and the tools to mitigate it will be useful throughout their career. As evidenced by the 2019 STS survey, the risk of experiencing burnout or depression will not go down after training. Secondly, training programs should intentionally devote resources to creating a strong sense of community amongst trainees. The sense of belonging that comes from being an engaged member of the team may not always reduce burnout, but it should increase the likelihood that a trainee will be more comfortable asking for help. Lastly, including an assessment of emotional well-being as part of the formal mentoring relationships between trainees and faculty will increase the likelihood that faculty are addressing these important issues with their mentees. Despite the risk of experiencing burnout during cardiothoracic surgery training, the future of cardiothoracic surgery remains promising. In the same 2019 STS survey, a majority of cardiothoracic surgeons stated they were very satisfied with their career, and would recommend a child to pursue the same career pathway. ${ }^{4}$ With increasing awareness regarding trainee burnout, we hope young surgeons and their training programs will develop the ability to recognize the symptoms and respond appropriately.

\section{References}

1. Freudenberger HJ. Staff burn-out. J Soc Issues. 1974;30:159-65. 
2. Dimou FM, Eckelbarger D, Riall TS. Surgeon burnout: a systematic review. J Am Coll Surg. 2016;222:1230-9.

3. Ikonomidis JS, Boden N, Atluri P. The Society of Thoracic Surgeons Thoracic Surgery practice and access task force-2019 workforce report. Ann Thorac Surg. May 10, 2020 [Epub ahead of print].
4. Swain JD, Soegaard Ballester JM, Luc JGY, Han JJ. Burning the candle at both ends: mitigating surgeon burnout at the training stages. J Thorac Cardiovasc Surg. 2021;162:637-42.

5. Qquendo MA, Bernstein CA, Mayer LES. A key differential diagnosis for physicians—major depression or burnout? JAMA Psychiatry. 2019;76:111.
See Article page 637.

\section{Commentary: Oxygen masks, counterculture revolutions, and cardiothoracic surgery trainees}

\author{
Elizabeth H. Stephens, MD, PhD
}

During every in-flight safety briefing, we hear the same refrain, "in the event of a loss of cabin pressure, put on your oxygen mask before assisting your children." The concept applies to cardiothoracic surgeons: to optimally care for our patients, we must put on our own mask first.

Swain and colleagues ${ }^{1}$ provide a review of burnout, with reflections from a training perspective. Although the paper covers familiar topics and reflects on how such issues can affect trainees, to my eyes the paper overlooks the elephant in the room: the broader culture in which the trainee resides. Cardiothoracic surgery is a high-risk, high-reward specialty that draws intense personalities that often thrive on adrenaline, danger, challenges, and the demand for perfection. Our culture is built on a history of almost-mythological giants who dared to dream big, took often unfathomable risks, and whose lifestyles reflected immense sacrifice for their dreams. The accounts of these giants live on, with the details of training under the icons of DeBakey, Cooley, Kirklin, Lillehei, Spencer, Sabiston, and many others, passed on to each freshly minted intern at their respective institution. The intensity and demands of training have been

From the Department of Cardiovascular Surgery, Mayo Clinic, Rochester, Minn. Disclosures: The author reported no conflicts of interest.

The Journal policy requires editors and reviewers to disclose conflicts of interest and to decline handling or reviewing manuscripts for which they may have a conflict of interest. The editors and reviewers of this article have no conflicts of interest.

Received for publication June 25, 2020; revisions received June 25, 2020; accepted for publication June 26, 2020; available ahead of print July 14, 2020.

Address for reprints: Elizabeth H. Stephens, MD, PhD, Department of Cardiovascular Surgery, Mayo Clinic, 200 First St, SW, Rochester, MN 55905 (E-mail: stephens. elizabeth@mayo.edu).

J Thorac Cardiovasc Surg 2021;162:644-5

$0022-5223 / \$ 36.00$

Copyright (c) 2020 by The American Association for Thoracic Surgery

https://doi.org/10.1016/j.jtcvs.2020.06.105
Check for updates

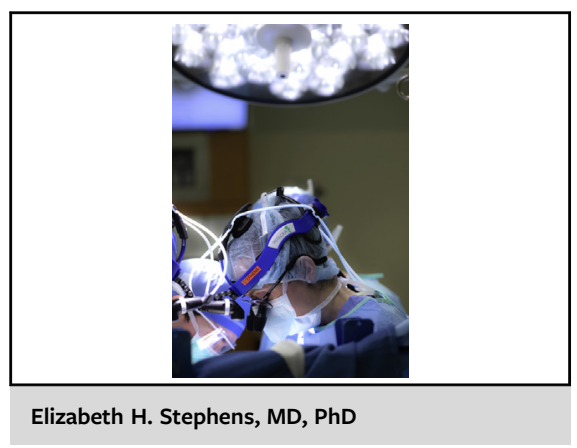

CENTRAL MESSAGE

Developing habits that

strengthen our fortitude as

cardiothoracic surgeons and

enable us to maintain peak per-

formance can run counter to the

culture in which we reside.

drastically curtailed, but the history in which we grow up remains, and the culture is slower to change. As part of this culture there is a masochism that is pervasive; it is exemplified by certain attendings, touted as a virtue by the staff who work with them, and often glorified among trainees. The trainee who sacrifices food, sleep, their personal commitments, etc, to go above and beyond for the sake of clinical duty is praised and rewarded. This isn't to say that sacrifice for the care of our patients isn't important- "the patient comes first" is in fact a founding tenant of my institution-but the issue becomes when such sacrifice goes to such lengths that it becomes detrimental to the trainee and/or the patient. For those in training eager to excel and gain the recognition of their attendings and outshine their peers, traits that potentially can become harmful can become entrenched. These traits are even more exaggerated when training at a high-octane academic institution with attendings frequently chasing after the illusive triple threat. 